\title{
Multi-criteria analysis of electricity generation mix scenarios in Tunisia
}

Originally published as:

Bernhard Brand, Rafik Missaoui (2014):

Multi-criteria analysis of electricity generation mix scenarios in Tunisia 
Bernhard Brand $^{a}$, Rafik Missaoui ${ }^{\text {b }}$

\section{Multi-criteria analysis of electricity generation mix scenarios in Tunisia}

\footnotetext{
a Wuppertal Institute for Climate, Environment and Energy, Germany

b ALCOR, Tunisia
}

* Corresponding author: Bernhard Brand, Wuppertal Institute, Döppersberg 19, 42103 Wuppertal, Germany

E-mail: bernhard.brand@wupperinst.org

Phone: +49 202-2492-109

Fax: +49 202-2492-108 


\section{Abstract}

The diversification of the national electricity generation mix has risen to the top of Tunisia's energy planning agenda. Presently, natural gas provides $96 \%$ of the primary energy for electric power generation, but declining domestic gas reserves and a soaring electricity demand are urgently calling for alternative fuel strategies. Currently discussed diversification options include the introduction of coal and nuclear power plants and/or an increased use of renewable energies. This article presents a methodology to assess different electricity system transformation strategies. By combining an electricity market model with a subsequent multicriteria decision analysis (MCDA), we evaluate five power mix scenarios regarding power generation costs as well as non-economic dimensions such as energy security, environmental impact and social welfare effects. Based on criteria valuations obtained during consultations with Tunisian stakeholders, a final, best-ranking electricity scenario was selected, consisting of $15 \%$ wind, $15 \%$ solar and $70 \%$ natural gas-generated electricity in the national power mix by 2030 .

\section{Introduction}

The Tunisian electricity sector is faced with a multitude of challenges, pressing for decisions about a new national power supply strategy. As for many other North African countries, one particular concern is the ever-growing electricity demand, which, despite successful efforts to reduce energy intensity in the past ${ }^{1}$, is still on a constant surge in Tunisia. Between 1990 and 2010, domestic power consumption almost tripled, from 4.9 TWh to $14 \mathrm{TWh}$; for the next two decades, the demand is expected to further grow, reaching 25-33 TWh by 2030 (STEG, 2010). The challenge to cope with this soaring demand is joined by another issue: Tunisia's unbalanced primary energy supply of power generation. Currently, the national electricity system is almost entirely fueled by natural gas, making up around $96 \%$ of the generation mix. This dependency will become particularly problematic in light of an imminent natural gas deficit that is forecasted for 2018 or 2020 (DGE, 2013), putting Tunisia's electricity supply security at risk. So far, the following options to render the Tunisian electricity mix more diverse have been proposed:

Tunisia was one of the first North African countries to subscribe to a national energy efficiency strategy, which it has pursued since the 1980s. 
(1) Coal Power. The use of imported hard-coal for power generation is already extensively practiced in another North African country, Morocco, and decision makers frequently discuss whether Tunisia should likewise adopt this model. A study by the national electricity and gas utility STEG (2010) evaluated the option to install up to three coal-fired steam power plants in the country, each with a capacity of $600 \mathrm{MW}$.

(2) Nuclear Power. This option is also discussed in Tunisia, since in 2006, the former government signed a bilateral agreement with France on the civilian use of nuclear power (Haddad, 2011). Under exploration is the installation of one pressurized water reactor with a tentative capacity of 900-1000 MW, slated to become operational by 2027 (STEG, 2010).

(3) Renewable Energies. Tunisia is endowed with excellent renewable resources. The country's wind potential is valued at $8 \mathrm{GW}$, with three main regions being particularly suitable for large wind farm projects: the North-East, the Central-West and the SouthWest of Tunisia. Solar radiation conditions are the best in Southern Tunisia, but generally very favorable across the entire territory. Gross estimations for Tunisia's solar potential reach $844 \mathrm{GW}$ for PV and $65 \mathrm{GW}$ for CSP technology (ANME, 2010) although these values must be assessed with care, as they usually do not include considerations about the actual availability of the land for solar power projects. The "Tunisian Solar Plan," a renewable energy roadmap drafted by the Tunisian energy conservation agency ANME, acknowledges the high renewable potential and points particularly to wind, photovoltaic and concentrated solar power (CSP) as diversification options to replace natural gas in the electricity mix (ANME, 2013a).

The extent to which these three diversification options - or a combination of them - can become part of a Tunisian electricity strategy is a matter of ongoing deliberations. The political context in which these discussions are taking place is marked by the Tunisian revolution of January 2011, which brought a new way of political decision making to the country along with considerable consequences for the culture of energy system planning. In the past, Tunisia's electricity strategies were discussed in closed circles accessed only by a small group of public decision makers, many of them with strong links to the national gas and electricity sector. The decision process itself was biased by the view of the incumbent national gas and electricity utility STEG, whose maxim for power system optimization was a least-cost planning approach, mostly disregarding social and environmental aspects. Nowadays, after the upheavals in early 2011, the interests of the civil society and other 
stakeholder groups can no longer be ignored. One aspect frequently raised in the discussions about power system choices are socio-economic benefits, most prominently the aspect of domestic added value, local manufacturing opportunities for the Tunisian industry, and its potential effects on job and income creation. Tunisia is suffering from a lack of jobs; the country's youth is plagued by a high unemployment rate, which, according to a study of the World Economic Forum (2012), is currently around 30\%. Aspirations for job creation and concerns of the local population (social acceptance) need to be given much more attention in the new democratic context. Also environmental aspects and the question of ecological sustainability of the national energy supply are increasingly discussed topics in the Tunisian society. Moreover, as a signatory of the Kyoto protocol, Tunisia has taken international responsibility to combat climate change by reducing its carbon emissions. A survey carried out in 2012 at a multi-stakeholder workshop within the framework of a project commissioned by the Tunisian energy conservation agency ANME and the German development agency GIZ (Wuppertal Institut/Alcor, 2012) revealed four major groups of criteria that are pertinent to electricity strategy development in Tunisia:

- Economic costs;

- Security of supply;

- Ecological sustainability; and

- Socio-economic benefits.

It is obvious that the above-listed goals are partially conflicting. Therefore, any decision on future electricity system transformation pathways can only be a compromise, which, at best, maximizes the satisfaction of the majority of the stakeholders, taking into account their varied preferences and objectives.

An analysis framework that includes these objectives must consider other criteria than just the economic costs of electricity generation. One possible approach would be to use external costs as guidance for decision-making on electricity strategy options (Mirasgedis and Diakoulaki, 1997). The valuation of externalities, however, is a difficult undertaking as it requires attributing quantified 'market' prices to the different societal and environmental impacts of electricity production. Although there have been attempts to quantify such externalities, for instance for public health and environmental impacts in Europe (Krewitt, 2002), estimations are generally associated with high uncertainties. Moreover, it is not clear whether the externality values obtained from a European project can properly reflect the North African conditions: for the Tunisian context, for instance, no valid quantifications of 
the external costs (or benefits) of social acceptance, job creation and energy security are available at the moment.

An alternative - and for our purpose a more suitable approach - is multi-criteria decision analysis (MCDA). Dealing likewise with strategy optimization problems, MCDA has been widely applied to social, economic, agricultural, industrial, ecological and biological systems, and likewise to energy supply systems (Wang et al. 2009). In the present study, we use MCDA in conjunction with an electricity generation system model to calculate and evaluate different Tunisian power system scenarios. This combined approach is presented in Section 2, where the basic features of the model as well as the MCDA method are described. Section 3 proceeds with an outline of the simulated scenarios and gives details about the assumptions and parameters used in the study. Section 4 presents the results, followed by a concluding discussion in the last chapter (Section 5).

\section{Methodology}

As pointed out in a literature review by Pohekar and Ramachandran (2004), the inclusion of multi-criteria techniques in energy system planning has gained increasing popularity in academic research since the 1990s. As for the area of electric energy supply (power generation), one can distinguish between two types of studies:

First, there are approaches that analyze and compare individual generation technologies based on their inherent economical, social and ecological properties. Recent examples of such studies can be found in Streimikiene et al. (2012), Pappas et al. (2012) and Boran et al. (2013), where renewable, fossil and nuclear power plant technologies are compared (or ranked) within a multi-criteria framework.

A second type of studies rather evaluates combined power systems instead of single technologies. Here, the multi-criteria analysis focuses on the performance of the overall power supply system, usually by examining different electricity mixes for a specific region or country. Finland, for instance, was the subject of a scenario study of Häyhä et al. (2011), where three alternative power system transformation pathways until 2050 with different levels of renewable, fossil and nuclear penetration underwent a multi-criteria analysis. A similar analysis has been carried out by Diakulaki and Karangelis (2007) for the Greek power system regarding economic, environmental, and energy security aspects. The development of the Spanish electricity system until 2030 was the focus of a study by Del Riego et al. (2012), 
while Ribeiro et al. (2012) analyzed electricity supply scenarios for Portugal until 2020 by combining a multi-criteria decision analysis with a linear power system optimization model.

In the present study, we opt for a two-step methodology, i.e. linking an electricity system model with a multi-criteria analysis, to analyze different Tunisian electricity mix scenarios with a time horizon of 2030. Figure 1 gives an overview of the methodological sequences of the analysis.

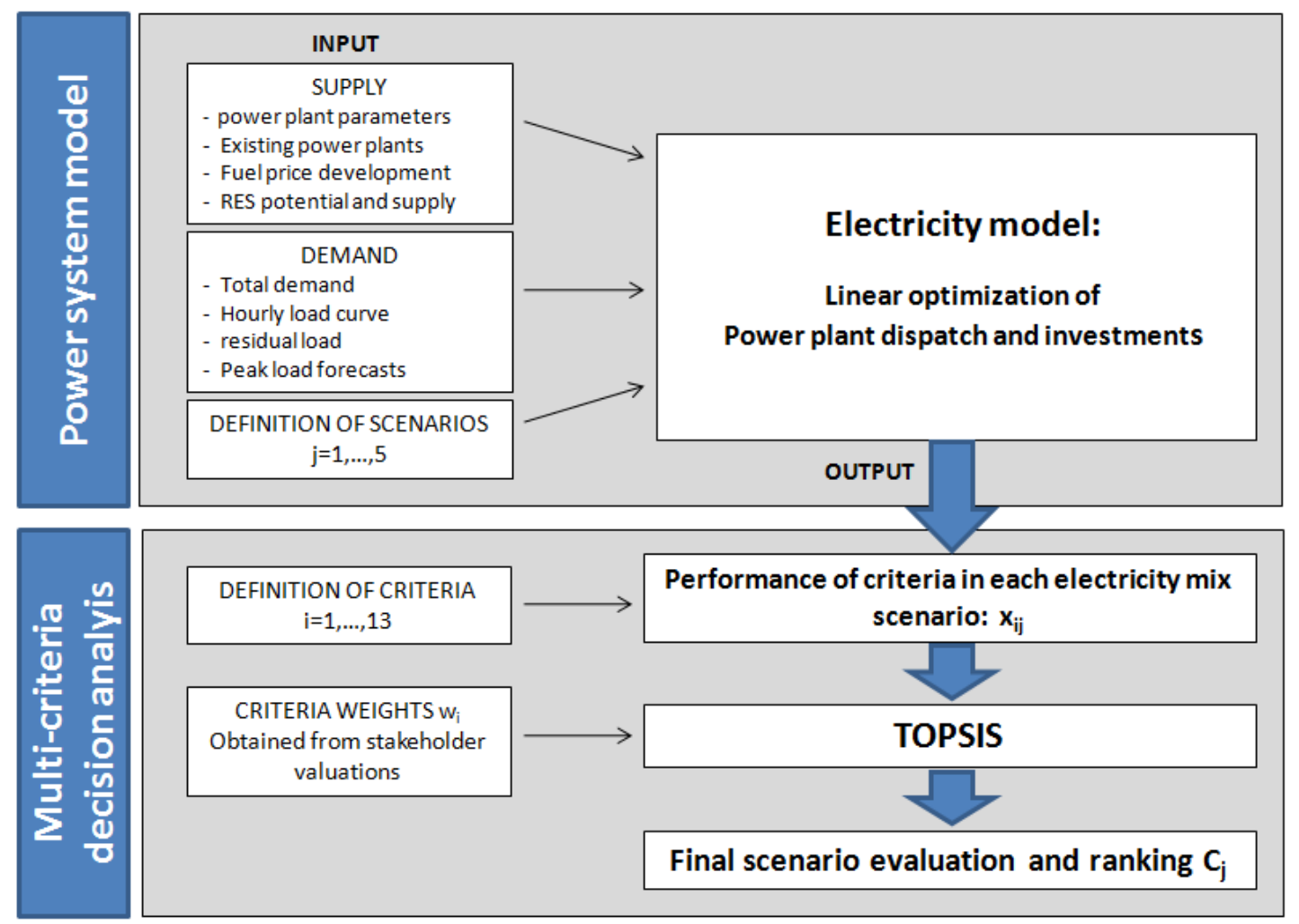

Figure 1. Process structure of the analysis

\subsection{Electricity Model}

There are several reasons why an electricity system modeling step has been placed prior to the multi-criteria analysis. First, the model was needed to calculate and quantify the most relevant values of the criteria: total system costs, primary energy consumption, emissions, etc. (for an overview, see Table 4). Second, the use of the model ensures that only technically viable and economically optimized power system configurations will be evaluated in the MCDA analysis. This is why both the daily power plant dispatch as well as the system transformation in the long-run - regarding commissioning and decommissioning of power plants - have been calculated under consideration of technical and economic constraints. Finally, the purpose of using an electricity system model was to provide the interested stakeholders with other 
relevant information concerning the impact of the electricity mix scenarios on the Tunisian economy, e.g. in terms of investments needed, infrastructure requirements, primary energy inputs and costs.

We use a bottom-up linear optimization model, which has already been applied and described in more detail in a previous generation system study of North African power systems (Brand et al., 2012). By minimizing the total discounted system costs, ${ }^{2}$

$$
\text { TOTAL }=\sum_{y=2010,2015, \ldots .} d i s c_{y} \cdot\left(I N V_{y}+O M_{y}+V A R_{y}+F U E L_{y}\right)
$$

the model calculates the optimal dispatch as well as the least-cost pathway for investments and the retirement of power plants in the Tunisian electricity system. Starting with the existing power plant stock of the year 2010, the simulation forecasts the configuration of the Tunisian power system until 2030 in 5-year periods. Each forecast period consists of 32 characteristic days, representing different electricity load profiles (working days and weekend days) as well as hourly wind-speed and solar irradiation patterns for 4 different seasons. The optimization process is carried out under the condition that the electricity supply meets the demand at any time:

$$
\operatorname{load}_{y, d, h}=\sum_{t e c h} G E N_{t e c h, y, d, h}
$$

The model variable $G E N_{t e c h, y, d, h}$ represents the actual electricity generation (in MWh) for the specific generation technology tech at any hour $(h=1, \ldots, 24)$ and typical day $(d=1, \ldots, 32)$ of the period $y$, while $\operatorname{load}_{y, d, h}$ is the exogenously determined electricity load pattern of Tunisia, derived from historic load data of the Tunisian electricity. Further boundary

2 The total system costs (the objective function) are the sum of investment costs (INV), fuel costs (FUEL) and variable costs (VAR), as well as costs for operation and maintenance (OM). The model does neither consider carbon emissions costs, nor revenues from avoided carbon emissions. The discount factor (disc) was calculated on the basis of an interest rate of $8 \%$. 
conditions are the technical constraints of the involved generation technologies. Thermal power plants need to respect constraints concerning part-load conditions and other dispatch properties like ramp-up and shut-down behavior, while renewable power generation is limited by the availability of the wind or solar resource. For wind speed and solar irradiation, we used hourly, historic data of the year 2010 matching to the date and hour of the electricity load of the corresponding representative day. Cost of transmission system expansion, as well as transmission losses were neglected in this simplified modeling approach.

The model delivers a number of physical parameters related directly to the future power system configuration as well as a set of non-physical, qualitative parameters relevant for the multi-criteria analysis:

- Physical parameters: For each forecast period, the model provides information about the installed generation capacities and power generation (per technology and per fuel) and primary energy consumption (overall and per energy carrier). Furthermore, the model calculates the quantities of gaseous emissions like carbon dioxide, but also nuclear waste.

- Non-physical and qualitative parameters: The most prominent non-physical parameters, directly available from the model output, are the economic costs of the power system scenarios. In addition, according to the proportions of each generation technology in the electricity mix, the model delivers a number of other parameters of qualitative or semi-qualitative nature, like the job creation potential, indicators for supply security, and the social acceptance of the different electricity mix scenarios.

Together with Tunisian stakeholders, a set of the 13 most relevant parameters, summarized in Table 4, were chosen as key evaluation criteria of the study's power system analysis.

\subsection{Multi-criteria decision analysis}

The problem of decision-making on energy strategies can be principally addressed by a variety of multi-criteria methods. An overview by Pohekar and Ramachandran (2004) presents a method inventory summarizing the most popular MCDA energy planning techniques: the analytical hierarchy process (AHP), the preference ranking organization method for enrichment evaluation (PROMETHEE), the elimination and choice translating reality (ELECTRE), the technique for order preference by similarity to ideal solution 
(TOPSIS), the weighted sum method (WSM), the weighted product method (WPM), compromise programming (CP), and the multi-attribute utility theory (MAUT).

In the present study, we decided to use the TOPSIS method developed by Hwang and Yoon (1981). TOPSIS was chosen primarily due to practical considerations, because it has "a sound logic, representing the rationale of human choice; a scalar value that accounts for the best and worst alternatives, and a simple computation process" (Kim et al., 1997) making it a suitable tool that can easily be understood and reproduced with reasonable effort also by users outside of the scientific sphere.

The scope of the TOPSIS method is to determine the "best scenario" among a set of scenarios, that is, the one closest as possible to an hypothetical ideal alternative and at the greatest distance to a negative-ideal alternative. This is realized by a geometrical mapping of each scenario's performance calculating its relative (Euclidean) distance to the ideal and negative-ideal solution. In detail, the procedure of the TOPSIS method consists of the following steps:

(1) Formulate a decision matrix which is formed by $j=1, \ldots, M$ columns for the scenarios and $i=1, \ldots N$ lines for the criteria. The matrix entries $x_{i j}$ are the raw results of the simulations with the Tunisian electricity system model (see Section 2.1.) and represent the performance of the criterion i with regard to scenario $\mathrm{j}$ (see Table 6).

(2) Calculate a normalized decision matrix. The TOPSIS method uses vector normalization to eliminate the units of the criteria, resulting in comparable matrix entries $r_{i j}$ normalized to $\left|r_{i j}\right| \leq 1$ :

$$
r_{i j}=x_{i j} / \sqrt{\sum_{j=1}^{M} \mathrm{x}_{i j}^{2}}
$$

(3) Construct the weighted normalized decision matrix.

$$
v_{i j}=w_{i} \cdot r_{i j}
$$


The weighting parameters $w_{i}$ for each criterion are derived from subjective preferences expressed by Tunisia experts within a voting process (see Section 3.3).

(4) Calculate the ideal and the negative-ideal solution. The ideal solution $A^{*}$ is a set of elements $v_{i}{ }^{*}$ selected from those elements of the normalized decision matrix $v_{i j}$, that provide the maximum benefit with respect to criteria $i$.

$$
A^{*}=\left\{v_{1}^{*}, \ldots, v_{N}^{*}\right\}
$$

Note that $v_{i}{ }^{*}$ must be selected from $v_{i j}$ by respecting the benefit attribute of each criterion. For example, regarding the criterion "job creation," the highest value $v_{i}^{*}=$ $\max _{\mathrm{j}} v_{i j}$ must be chosen (benefit attribute is positive: "more jobs are better"); for $\mathrm{CO}_{2}$ emissions (negative benefit attribute: "less $\mathrm{CO}_{2}$ emissions are better"), the lowest possible value $v_{i}^{*}=\min _{j} v_{i j}$ must be selected. Reciprocally, the negative ideal solution

$$
A^{-}=\left\{v_{1}^{-}, \ldots, v_{N}^{-}\right\}
$$

is a selected set of $v_{i}^{-}$associated with the lowest benefit among all $v_{i j}$.

(5) For each scenario $j=1, \ldots \mathrm{M}$, calculate the Euclidean distance to the ideal alternative $A^{*}$,

$$
D_{j}^{*}=\sqrt{\sum_{i=1}^{N}\left(v_{i j}-v_{i}^{*}\right)^{2}}
$$

as well as the negative ideal alternative $\mathrm{A}^{-}$ 


$$
D_{j}^{-}=\sqrt{\sum_{i=1}^{N}\left(v_{i j}-v_{i}^{-}\right)^{2}}
$$

(6) Compare the separation values $D_{j}^{*}$ and $D_{j}^{-}$by calculating the relative closeness to the ideal solution:

$$
C_{j}=\frac{D_{j}^{-}}{D_{j}^{*}+D_{j}^{-}}
$$

(7) Finally, establish a ranking list, with the highest $C_{j}$ indicating the best-ranking scenario $j$.

The input parameters needed for the TOPSIS method are the performance $x_{i j}$ of the different criteria $i$, and their respective weights $w_{i}$ in each scenario $j$. While $x_{i j}$ are obtained from the results of the power system model (see Section 4.2), the weights $w_{i}$ of the criteria are derived from Tunisian stakeholders valuations (Section 3.3).

\section{Scenarios, input parameters, and criteria}

In a project preceding this study ${ }^{3}$, five different scenarios for the Tunisian electricity mix until 2030 were defined by the key stakeholders of the Tunisian power sector (Ministry of Energy, Ministry of Industry, STEG, ANME, etc.). These scenarios reflect the discussed policy options for power system transformation along the main diversification axes: nuclear energy, coal power and/or the increased use of renewable energies for electricity generation. A business as usual (BAU) case represents the scenario where no action is taken, and the current electricity mix (i.e. natural gas-generated power with a minor contribution of wind power) is maintained until 2030 (see Table 1).

3 The previous study was commissioned by the German development agency Deutsche Gesellschaft für Internationale Zusammenarbeit (GIZ) in 2011. 
Table 1. Scenarios.

\begin{tabular}{|c|c|c|}
\hline Scenario & $j$ & Description \\
\hline $\begin{array}{l}\text { BAU (Business } \\
\text { as usual) }\end{array}$ & 1 & Reference scenario, current power mix carried forward to $2030: 95 \%$ gas, $5 \%$ wind \\
\hline DivCoal & 2 & $\begin{array}{l}\text { Diversification with an important contribution of coal power plants to be build starting } \\
\text { from } 2020 \text {. Targeted electricity mix by } 2030: 60 \% \text { coal, } 35 \% \text { gas, } 5 \% \text { wind. }\end{array}$ \\
\hline DivNuc & 3 & $\begin{array}{l}\text { Nuclear power for diversification, } \sim 1000 \mathrm{MW} \text { reactor to be built in } 2025 \text {. Targeted } \\
\text { electricity mix by } 2030 \text { : gas } 75 \% \text {, nuclear } 25 \% \text {, wind } 5 \% \text {. }\end{array}$ \\
\hline DivCoalRes & 4 & $\begin{array}{l}\text { Combined diversification with coal and renewable power. Targeted electricity mix by } \\
2030: 50 \% \text { coal, } 10 \% \text { wind, } 5 \% \text { solar }(3 \% \text { PV }, 2 \% \text { CSP }), 35 \% \text { gas. }\end{array}$ \\
\hline DivRes & 5 & $\begin{array}{l}\text { Diversification with } 30 \% \text { renewable power. Targeted electricity mix by } 2030 \text { : gas: } \\
70 \% \text {, wind } 15 \% \text {, solar } 15 \%(10 \% \text { PV, } 5 \% \text { CSP }) \text {. }\end{array}$ \\
\hline
\end{tabular}

\subsection{Input parameters}

\subsubsection{Demand}

It is obvious that a more efficient use of electricity is important for Tunisia to alleviate energy dependency, save fuel costs, and mitigate the need for new generation capacity and grid expansion. Tunisia traditionally puts high efforts into promoting energy efficiency. Despite certain concerns about the 'rebound effect' of energy efficiency measures (Wang et al., 2014), the Tunisian government pursues an active policy to reduce electricity consumption in households as well as in the industry (GIZ/ANME, 2012). In our study, we use a demand forecast by the Tunisian Energy conservation agency ANME (2013b). This demand scenario assumes an energy efficiency pathway with a decoupling of the Tunisian electricity demand from economic growth, translating into an average decrease of the electricity intensity of $2 \%$ per year between 2013 and 2030. The resulting demand and load input parameters for the electricity model are displayed in Table 2.

Table 2. Assumptions for annual gross demand growth and peak load development.

\begin{tabular}{|c|c|c|c|}
\hline & 2010 & 2020 & 2030 \\
\hline Annual demand (TWh) & 14.8 & 20.7 & 28.9 \\
\hline Peak load (MW) & 3010 & 4900 & 6840 \\
\hline
\end{tabular}


Regarding the daily variations of the demand, hourly historic load profiles of the year 2010, provided by the Tunisian electricity utility STEG, were used. These profiles were linearly scaled up according to the expected increases of the annual demand in the future model periods until 2030.

\subsubsection{Generation}

As mentioned, the model assumes that power supply is exclusively realized by domestic power plants; electricity exchanges with neighboring countries (power imports or exports) are neglected. For simplicity we also consider that the model can only deploy a limited set of different generation technologies: gas power plants (open cycle and combined cycle power plants ${ }^{4}$ ), coal steam power plants, nuclear power plants, photovoltaic (PV), concentrating solar power (CSP) and wind turbines. The technical and economic modeling parameters of these power plants are displayed in Table 3. Data originated from a previous report about Tunisian power system strategies (Wuppertal Institut/Alcor, 2012) and were agreed upon in a workshop with Tunisian power system experts. The same applied for the fuel price assumptions (for natural gas, steam coal and uranium), which were derived from an analysis of market price forecasts from different organizations, such as the International Energy Agency (IEA), the US Department of Energy (US-DOE), and the World Bank. An average reference scenario representing moderate price increases until 2030 (see Table 3) was chosen and agreed upon by the Tunisian stakeholders.

Additional supply input parameters are solar irradiation and wind speed. Solar output patterns were calculated with the System Advisor Model of the US National Renewable Energy Laboratory (NREL) based on global horizontal irradiation (GHI) for PV or direct normal irradiance (DNI) for CSP power plants (NREL, 2012). Irradiation time series were provided by Helioclim (2012) for an exemplary site near the city of Tataouine, Southern Tunisia in the year 2010. It is assumed that PV power plants are composed of crystalline cell modules and installed ground-mounted, while CSP power plants are standard dry-cooled parabolic trough technology, with 6 hours thermal storage and a solar multiple of 2 . The methodology of CSP dispatch modeling is described in Brand et al. (2012). Hourly wind power production patterns were calculated with the MINT software (Sander+Partner, 2012), based on MERRA wind

$4 \quad$ Additionally, the model takes account of the existing stock of older, gas-powered steam plants in the Tunisian power system. 
speed time series of NASA (2012) for typical commercial wind turbines (Vestas V80, 2 MW) at three typical wind power sites in Tunisia: Bizerte, Haouaria and Kebili. 


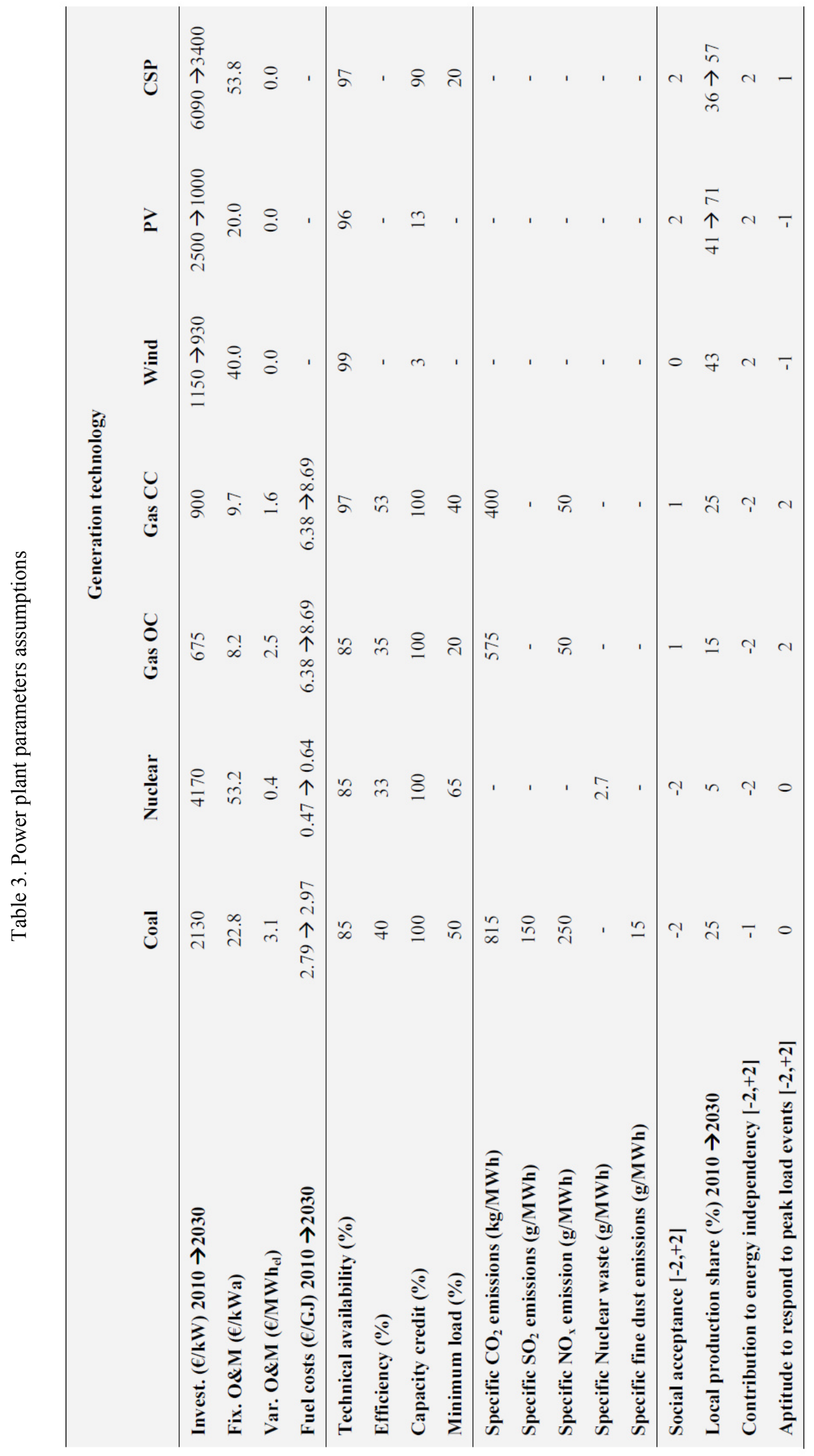




\subsection{Criteria}

Our analysis covers 13 different criteria pertaining to four main groups: economic costs, supply security, socio-economic criteria and ecological criteria (see Table 4).

Table 4. Criteria and criteria groups

\begin{tabular}{|c|c|c|c|c|}
\hline Criteria group & $i$ & Criteria & Unit & Benefit attribute* \\
\hline \multirow[t]{2}{*}{ A. Economic costs } & 1 & Net present value of total costs & billion $€$ & NEG \\
\hline & 2 & Specific generation costs & $€ / \mathrm{MWh}$ & NEG \\
\hline \multirow[t]{3}{*}{ B. Supply security } & 3 & Aptitude to respond to peak load events & point $[-2 \ldots .2]$ & POS \\
\hline & 4 & Total natural gas consumption & PJ & NEG \\
\hline & 5 & Contribution to energy independency & point $[-2 \ldots .2]$ & POS \\
\hline \multirow[t]{3}{*}{$\begin{array}{l}\text { C. Socio-economic } \\
\text { criteria }\end{array}$} & 6 & Local manufacturing share & $\%$ & POS \\
\hline & 7 & Social acceptance & point $[-2 \ldots 2]$ & POS \\
\hline & 8 & Average jobs created & number & POS \\
\hline \multirow[t]{5}{*}{ D. Ecological criteria } & 9 & $\mathrm{CO}_{2}$ emissions & $\mathrm{Mt} \mathrm{CO}$ & NEG \\
\hline & 10 & $\mathrm{SO}_{2}$ emissions & $\mathrm{t} \mathrm{SO}_{2}$ & NEG \\
\hline & 11 & $\mathrm{NO}_{\mathrm{x}}$ emissions & $\mathrm{t} \mathrm{NO}_{\mathrm{x}}$ & NEG \\
\hline & 12 & Nuclear waste & t nuc. waste & NEG \\
\hline & 13 & Fine dust emissions & $\mathrm{t}$ fine dust & NEG \\
\hline
\end{tabular}

${ }^{*}$ benefit attribute for TOPSIS analysis: NEG: 'less is better'; POS: 'more is better'

\subsubsection{Economic costs}

Total system costs (1)

The total system costs are the discounted sum of investment annuities, fuel costs, and operation and maintenance (O\&M) costs accumulated over the entire model period until 2030. From the standpoint of a national planner, these net capital costs are the most relevant economic indicator, as they allow a direct assessment of how much the different scenarios would cost the Tunisian economy. The electricity model calculates the total costs as net present value for the year $2010\left(€^{2010}\right)$, using a discount rate of $8 \%$. 
Specific generation costs (2)

Another important cost indicator is the specific electricity generation costs, a per-unit value expressed in $€ / \mathrm{MWh}$. They can be regarded as a proxy of the electricity costs to be incurred by the Tunisian electricity consumer. The criteria input used in this study is the average of the annual specific cost between the years 2010 and 2030.

\subsubsection{Supply security}

Supply security is a prominent objective in energy planning in Tunisia. For simplicity, we subsume under this criteria group short-term aspects, as the technical ability of the power system to provide capacity at any time (peak load response), as well as the following longterm energy independency aspects.

\section{Aptitude to respond to peak-load events (3)}

For this criterion, we give each generation technology a qualitative attribute (scores between 2 and +2 ) for its aptitude to respond to peak load events. Gas power plants, with their high capability to follow load variations, receive a score of +2 , while less flexible base-load technologies (coal, nuclear) are given 0 points. The score of intermittent renewable power technologies is -2 , because they cannot fully guarantee reserve capacity at any time. Based on these numbers, we calculate for each scenario an aggregated indicator for each scenario by averaging the different technology scores according to their proportions of installed capacity in the generation system until 2030.

\section{Total natural gas consumption (4)}

As outlined in Section 1, it is a key objective of Tunisia's energy policy to reduce the consumption of natural gas in order to delay dwindling of domestic gas reserves and to alleviate long-term dependency on gas imports (from Algeria). Therefore, the total gas consumption in terms of primary energy for electricity generation is a characteristic criterion for energy security. The indicator used in the TOPSIS analysis is the overall gas consumption (in PJ) until the year 2030.

\section{Contribution to energy independency (5)}

Substituting natural gas with other energy carriers does not increase the security of supply if these carriers expose to Tunisia to new dependencies. The criterion "contribution to energy independency" provides for each primary energy source a subjective ranking between -2 and 
+2 . Renewable energies receive the highest score $(+2)$, as they diversify with domestic energy carriers. As the reduction of natural gas consumption is the key target of Tunisia's diversification efforts, generation technologies using natural gas are given a score of -2 . Coal has the inconvenience of being imported, but the risk of becoming energy-dependent is attenuated by the fact that steam coal is available from numerous exporting countries worldwide (score -1). In contrast, uranium, the fuel for nuclear technology, is only available from rather monopolized markets, which raises the proneness toward energy dependency (score -2). The overall score is calculated by building an average of the individual scores, weighted by the fuel consumption proportions for each scenario in the overall electricity production until 2030.

\subsubsection{Socio-economic criteria}

This criteria group, consisting of three sub-criteria, addresses socio-economic welfare incurred by the different electricity scenarios.

\section{Local production share (6)}

The local production share (or local content) indicates how much of the investment into new generation capacity would flow back to the Tunisian manufacturing industry. The estimates (expressed in percentage points) are based on ratings provided by Tunisian power and renewable energy experts (see Table 3). For solar technologies, a gradually increasing local manufacturing share is assumed from today's levels until 2030 (Fraunhofer/Ernst \& Young, 2011). The final local production share for each power mix scenario is calculated by averaging the individual technology scores according to their proportions of the installed capacities until 2030.

\section{Social acceptance (7)}

Social acceptance is given a rating between -2 and +2 in an effort to reflect the population's expected attitude vis-à-vis the occurrence of new power plant technologies in the country. The worst value (-2) is received by nuclear power plants, whose implementation is presumed to be disapproved both by the local population as well as the Tunisian society in general (Haddad, 2011). A zero score (0) is given to technologies which are regarded indifferently or where reservations by the local population (noise, visual disturbance) are outweighed by a generally positive reputation of the technology on the national level, for example, wind power. Solar 
technologies are ranked highest with a rating of +2 . The total social acceptance rating per scenario is calculated as an average of the annual acceptance ratings until 2030.

\section{Job creation (8)}

The estimation of the job creation potential for the different scenarios is based on the method used by Rutovitz and Harris (2012). For each scenario, the total number of jobs is calculated as the sum of jobs in the power plant construction sector, the component manufacturing industry, and the labor needed for operation and maintenance (O\&M) of the already installed power plants. Jobs in the construction sector are obtained by multiplying the capacity (in MW) of new power installations with a technology-specific employment multiplier, corrected by a regional adjustment factor listed in the above-mentioned study of Rutovitz and Harris (for Tunisia, the correction factor of the Middle East region was applied). The jobs created in the power plant component manufacturing industry receive an additional adjustment considering the local production share in Tunisia (see criteria 6 in Table 6). Jobs in the O\&M sector are calculated by applying an O\&M employment factor to the existing, operational power plant capacities. Finally, for each scenario, a final overall criteria score $x_{i j}$ is established by calculating the average number of jobs in the electricity sector until 2030.

\subsubsection{Ecological criteria}

This criteria group encompasses the most relevant emissions of the different power plant technologies: $\mathrm{CO}_{2}$ emissions (9), $\mathrm{SO}_{2}$ emissions (10), $\mathrm{NO}_{x}$ emissions (11), nuclear waste (12), and fine dust (13). For each category and scenario, total emissions until 2030 are calculated based on the technologies' specific emissions per MWh (see Table 3).

\subsection{Criteria weights}

Assigning weighting parameters for the criteria is a difficult undertaking, as it requires knowledge about the decision-makers' preferences on energy policy issues. Unfortunately, looking at the ongoing political transition process in Tunisia, it was (at the moment of this writing) impossible to discern the orientations of a yet-to-be elected Tunisian government. Therefore, our study was constrained to fall back to a relatively coarse and simplified method to elicit the weighting parameters. The method consisted of carrying out a voting among 37 Tunisian experts during a stakeholder workshop held in Tunis. As illustrated in Figure 2 the involved stakeholders were representatives of different institutions and organization: the 
national electricity utility STEG, its renewable branch STEG Energies Renouvelables, the Ministry of Industry, the Ministry of Environment, the national agency of energy conservation (ANME), the Ministry of Planning and Regional Development, the Ministry of Finance, as well as individual consultants and industry representatives.

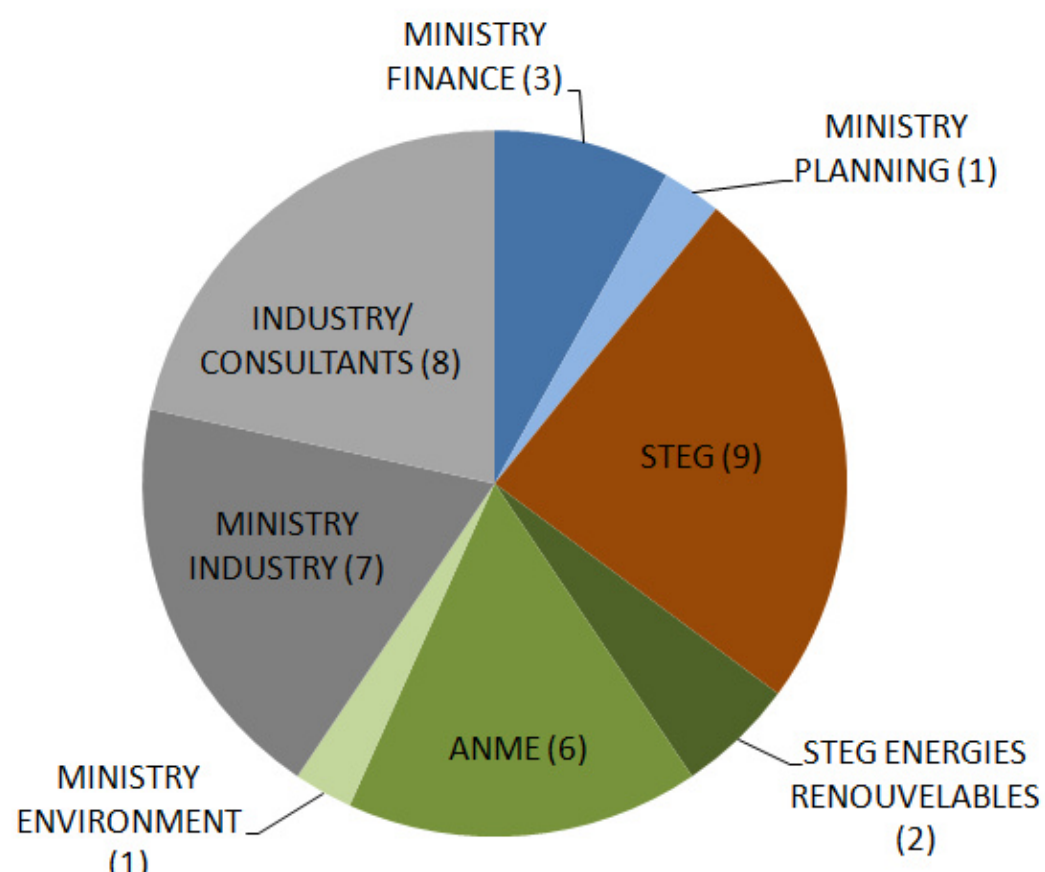

(1)

Figure 2. Participants of expert workshop by institution

Although it is difficult to establish a direct link between institutional affiliations and the participants' individual preferences, it can be presumed that, for example representatives of the renewable energy sector, the Ministry of Environment or ANME rather tend to favor environmental criteria, while members of the electricity utility STEG might be more concerned by aspects of security of supply. Industry representatives might also emphasis supply security criteria, but should be also concerned by cost aspects and socio-economic criteria. Cost criteria are likely to be the priority for members of the finance and planning ministries.

In order to avoid that the votes follow too closely the orientations of the involved institutions, each expert was asked to designate not only one, but two favorite criteria groups he deems most important for a future Tunisian energy strategy. A final count of these votes revealed the following ranking among the criteria groups: Minimizing economic costs was given the highest priority (34\%), followed by concerns about supply security (27\%); socio-economic 
considerations (20\%) and environmental aspects (19\%) were valued significantly lower. Subsequently, the weights for the criteria groups were apportioned equally to the different sub-criteria in order to obtain the 13 individual weighing parameter $\mathrm{w}_{\mathrm{i}}$ used in the TOPSIS analysis.

Table 5. Weighting parameters for criteria groups

\begin{tabular}{|c|c|c|c|c|c|}
\hline & \multirow{2}{*}{$\begin{array}{c}\text { Reference } \\
\text { Expert } \\
\left.\text { voting }^{*}\right)\end{array}$} & \multicolumn{4}{|c|}{ Sensitivity cases } \\
\hline & & $\begin{array}{l}\text { Holistic } \\
\text { approach }\end{array}$ & $\begin{array}{l}\text { Technocratic } \\
\text { approach }\end{array}$ & $\begin{array}{c}\text { Mercantilist } \\
\text { approach }\end{array}$ & $\begin{array}{l}\text { Eco-social } \\
\text { approach }\end{array}$ \\
\hline A. Economic costs & $34 \%$ & $25 \%$ & $40 \%$ & $10 \%$ & $10 \%$ \\
\hline B. Supply security & $27 \%$ & $25 \%$ & $40 \%$ & $40 \%$ & $10 \%$ \\
\hline $\begin{array}{l}\text { C. Socio-econ. } \\
\text { benefits }\end{array}$ & $20 \%$ & $25 \%$ & $10 \%$ & $40 \%$ & $40 \%$ \\
\hline D. Ecological criteria & $19 \%$ & $25 \%$ & $10 \%$ & $10 \%$ & $40 \%$ \\
\hline
\end{tabular}

${ }^{*)}$ obtained at a stakeholder workshop in Tunis.

Due to the above-mentioned uncertainties about the actual Tunisian policy preferences, we decided to repeat the multi-criteria analysis with distinct assumptions regarding the weighting parameters for criteria groups. Four different sensitivity cases were analyzed: (1) a 'holistic approach', where each criteria group receives the same weight, (2) a 'technocratic approach' characterized by a strong emphasis on economic costs and security of supply, (3) a 'mercantilist' approach where decision making is oriented towards social-economic benefits and the security of Tunisia's energy supply, and (4) an "eco-social" approach where ecological and social criteria dominate (see Table 5).

\section{Results}

\subsection{Power system transformation pathways}

Figure 3 depicts the outcome of the linear optimization process, giving an overview of the system configuration (installed capacities) as well as the generated electricity by power plant and fuel type from 2010 until 2030. Looking at the installed capacities (Figure 3, left), it becomes obvious that the need for new power plant capacity in Tunisia is substantial. Not 
surprisingly, the scenario with the highest capacity requirements is the renewable diversification scenario (DivRes). Due to their low capacity factor, a comparatively high number of wind and solar power plants needs to be installed in order to meet the $30 \%$ renewable electricity share by 2030 . Furthermore, as these technologies also feature a low capacity credit $^{5}$ (see Table 3 ) more conventional back-up power capacity (mostly OC gas turbines) is required to ensure the reliability of the system in case of peak load events.

The development of the power generation mix (Figure 3, right) indicates that natural gas still remains the dominant fuel if the cumulated gas-based generation between 2010 and 2030 is regarded. This means that Tunisia will still require a substantial amount of natural gas during the transition period until the diversification goals are reached in 2030. This accounts even for those scenarios that portray a strong substitution of natural gas with coal by 2030 (DivCoal and DivCoalRes). Tunisian decision makers should be aware that due to the long lead times for coal power plant construction (the first plants are unlikely to become operational before 2018), the provision of natural gas still remains a crucial issue for the near future.

5 The capacity credit is the ability of a generation technology to provide firm capacity to the power system. 

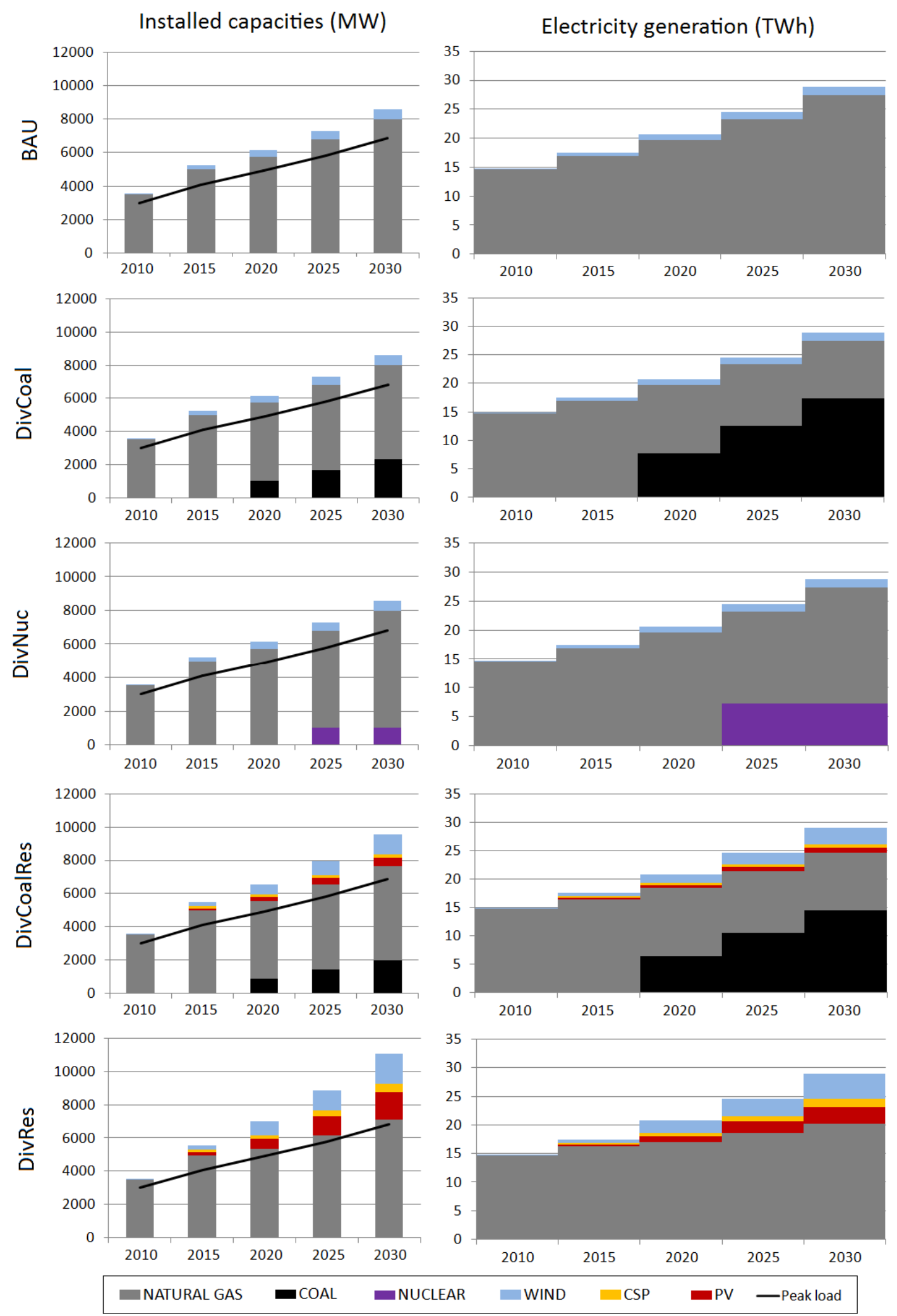

Figure 3. Installed capacities (left) and generation (right) for the different scenarios of the Tunisian electricity system until 2030. 


\subsection{Scenario performance by criteria}

Table 6 summarizes the model results for the different criteria. Each element of the table represents the performance value $x_{i j}$ of the criterion $i$ with respect to scenario $j$. It is obvious that due to the multitude of the criteria, their different dimensions, and resulting performances scores, no easy conclusion about the best performing scenario can is possible - at least not by a simple look at the table. This underscores the need for a multi-criteria method to evaluate the different scenarios in a more analytical fashion.

Table 6. Results of the electricity system calculations: Performance of the criteria for each scenario.

\begin{tabular}{|c|c|c|c|c|c|c|}
\hline \multirow[b]{4}{*}{ Criteria $i$} & \multicolumn{5}{|c|}{ Scenario $j$} & \multirow[b]{4}{*}{ Unit } \\
\hline & 1 & 2 & 3 & 4 & 5 & \\
\hline & BAU & DivCoal & DivNuc & DivCoalRes & DivRes & \\
\hline & \multicolumn{5}{|c|}{ Performance $x_{i j}$ of criteria $i$ in scenario $j$} & \\
\hline 1 & 13.9 & 13.1 & 13.7 & 13.6 & 14.4 & billion $€$ \\
\hline 2 & 69.9 & 64.4 & 68.1 & 67.0 & 72.4 & $€ / M W h$ \\
\hline 3 & 1.63 & 1.36 & 1.53 & 1.20 & 1.13 & point $[-2 \ldots 2]$ \\
\hline 4 & 2822 & 1846 & 2447 & 1831 & 2424 & PJ \\
\hline 5 & -1.85 & -1.55 & -1.85 & -1.39 & -1.36 & point $[-2 \ldots 2]$ \\
\hline 6 & 21.7 & 21.4 & 18.9 & 24.7 & 29.5 & $\%$ \\
\hline 7 & 0.75 & 0.42 & 0.53 & 0.81 & 1.08 & point $[-2 \ldots 2]$ \\
\hline 8 & 3650 & 5690 & 5460 & 7360 & 8890 & jobs \\
\hline 9 & 167 & 226 & 144 & 206 & 143 & $\mathrm{Mt} \mathrm{CO} 2$ \\
\hline 10 & 0 & 22 & 0 & 18 & 0 & $\mathrm{kt} \mathrm{SO} \mathrm{S}_{2}$ \\
\hline 11 & 19 & 48 & 16 & 42 & 16 & $\mathrm{kt} \mathrm{NO}_{\mathrm{x}}$ \\
\hline 12 & 0 & 0 & 149 & 0 & 0 & t nuc. waste \\
\hline 13 & 0 & 2150 & 0 & 1800 & 0 & $\mathrm{t}$ fine dust \\
\hline
\end{tabular}

\subsection{Results of the Multi-criteria analysis}

By applying the TOPSIS method to the results of Table 6 and considering the weighting parameters $w_{i}$ obtained at the expert workshop (Table 5), we calculate the final scenario scores in Table 7. The highest ranking is the diversification scenario with renewable energies (DivRes), followed by the business as usual scenario (BAU) and the diversification scenario combining renewable energies with coal power contribution (DivCoalRes). At the bottom of 
the ranking with relatively close scores are the nuclear (DivNuc) and coal (DivCoal) strategies.

Assuming that our criteria framework and the applied weighting parameters actually match with the rationale of the Tunisian decision-makers, it can be stated that the electricity mix diversification strategy with renewable energies should actually receive high emphasis in deliberations about future Tunisian energy policies.

Table 7. Scenario score for TOPSIS (weighting parameters obtained from expert voting)

\begin{tabular}{lccc}
\hline \multicolumn{1}{c}{ Scenario } & $\boldsymbol{j}$ & Scenario score & Rank \\
\hline $\begin{array}{l}\text { BAU (Business as } \\
\text { usual) }\end{array}$ & 1 & 0.633 & $\mathbf{2}$ \\
DivCoal & 2 & 0.444 & $\mathbf{5}$ \\
DivNuc & 3 & 0.484 & $\mathbf{4}$ \\
DivCoalRes & 4 & 0.555 & $\mathbf{3}$ \\
DivRes & 5 & 0.773 & $\mathbf{1}$ \\
\hline
\end{tabular}

\subsection{Sensitivities: Ranking for different policy preferences}

Although the analysis in the previous section reveals a clear preference in favor of the renewable diversification scenario (DivRes), one could argue that this outcome is distorted by the criteria weight selection, which features a certain bias of the stakeholders in favor of ecological and social criteria; thus, it may have put the renewable scenario in an overly optimistic light. What would be the outcome of the TOPSIS analysis if other policy preferences, such as those described in Section 3.3 (Table 5), were used to determine the weighting parameters? In order to answer this question, additional rankings for different sensitivity cases are calculated. 
Table 8. Ranking of the different sensitivity cases

\begin{tabular}{|c|c|c|c|c|c|}
\hline \multirow[b]{2}{*}{ Rank } & \multirow{2}{*}{$\begin{array}{c}\text { Reference } \\
\text { Expert voting }\end{array}$} & \multicolumn{4}{|c|}{ Sensitivity cases } \\
\hline & & $\begin{array}{c}\text { Holistic } \\
\text { approach }\end{array}$ & $\begin{array}{c}\text { Technocratic } \\
\text { approach }\end{array}$ & $\begin{array}{c}\text { Mercantilist } \\
\text { approach }\end{array}$ & $\begin{array}{l}\text { Eco-social } \\
\text { approach }\end{array}$ \\
\hline 1 & DivRes & DivRes & DivCoalRes & DivRes & DivRes \\
\hline 2 & BAU & BAU & DivRes & DivCoalRes & BAU \\
\hline 3 & DivCoalRes & DivCoalRes & DivCoal & BAU & DivCoalRes \\
\hline 4 & DivNuc & DivNuc & BAU & DivCoal & DivNuc \\
\hline 5 & DivCoal & DivCoal & DivNuc & DivNuc & DivCoal \\
\hline
\end{tabular}

The results in Table 8 demonstrate a relatively high robustness, at least with regards to the first rank: except for the 'technocratic' approach, which prioritizes the coal-RES diversification scenario (DivCoalRes) because of its favorable supply security and energy independency attributes, all other sensitivity cases exhibit a clear preference for the renewable diversification scenario (DivRes). Regarding the second and third rank, both are predominantly occupied by the business as usual (BAU) and the coal-renewable diversification scenario (DivCoalRes). The two last ranks are shared between the DivCoal and the DivNuc scenario.

In summary, the overall analysis framework indicates that the renewable diversification scenario (DivRes) represents a favorable strategy for the majority of all possible decisionmaking environments. The DivRes scenario is followed by the business-as-usual (BAU) baseline case and the combined diversification scenario with coal and renewable energies (DivCoalRes). The nuclear power and the exclusively coal-based diversification (DivCoal) scenarios appear to be the least advantageous strategies for the transformation of the Tunisian electricity system until 2030.

\section{Conclusion}

The methodology presented in this article aims to support the complex decision making process that is currently ongoing concerning Tunisia's future energy strategies. After the Tunisian revolution in 2011 , the country is standing not only at a crossroad in the political sense but also in terms of energy supply; thus, important decisions need to be made. Regarding the electricity sector, prime concerns are the dependency on natural gas, cost aspects, and the social aspects of future electricity supply schemes, in particular with regard to 
job creation. Environmental sustainability issues are also increasingly promoted by Tunisia's civil society.

In this study, we subjected five different electricity system transformation scenarios to a twostage analysis method which consisted of a cost-minimizing electricity market model used in conjunction with a multi-criteria analysis. In order to address the multiple aspects of the decision making context in Tunisia, it was necessary to establish a mapping of the Tunisian stakeholder preferences prior to the analysis. This was carried out within a participative stakeholder process, organized by the Tunisian energy conservation agency ANME during expert consultations about a new national renewable energy roadmap: the Tunisian Solar Plan. The criteria preferences (obtained by expert voting) served as weighting parameters for the above-mentioned multi-criteria analysis, and allowed us to establish an indicative ranking of the scenarios. The scenario providing the maximum utility for the examined group of stakeholders was the "Renewable Diversification Scenario," targeting a renewable contribution of $30 \%$ in the overall power generation mix in 2030 .

As our multi-criteria analysis rests on criteria valuations of a relatively limited set of experts, there remain uncertainties as to whether the obtained ranking result really mirrors the intentions of the Tunisian society as a whole. In a sensitivity analysis, we calculated hypothetical cases where the criteria preferences are very asymmetrically biased toward mercantilist, eco-social and technocratic criteria. The results show a relatively high robustness of the ranking, placing the renewable diversification scenario in a superior position for most of the analyzed alternative decision environments. One exception is the "technocratic" decision environment, where the coal-renewable diversification (DivCoalRes) is preferred to the renewable diversification (DivRes). Interestingly, the MCDA study of Ribeiro et al. (2012) about the Portuguese power system comes to a similar result: here, the "maximum renewable scenario" is challenged by an equally high-ranking "coal scenario". The studies featuring Finland (Häyhä et al., 2011) and Greece (Diakulaki and Karagelis, 2007), however, both exhibit a clear preference of the RES-E scenarios compared to other alternatives of the multi-criteria decision framework. In the Spanish study (Del Riego et al., 2012), where a system development model is combined with a dynamic TOPSIS-based decision making tool, renewable technologies also clearly increase their weight in electricity generation. Our results, together with the above-mentioned findings from similar studies in other countries, should be seen a strong indicator that renewable energy mix visions actually merit a stronger consideration in the discussions about future Tunisian energy policies. 
To conclude, it must be noted that our analysis has the drawback of being a purely national approach. The effects of integrating the Tunisian electricity system into a larger regional or even trans-Mediterranean electricity supply scheme were not within the scope of this study. Additional investigations are desirable with this respect, e.g. to assess the effects of a stronger embedding of the Tunisian power system in an international electricity supply scheme with more cross-border power trade (imports and exports of electricity). In this case, interactions of the different national policy strategies also need to be taken into account, e.g. between the Tunisian energy roadmap and those of its neighboring countries Algeria and Libya. Further work is also required to assess the impact of common trans-Mediterranean power system roadmaps, like Desertec (Dii, 2013) or the Mediterranean Solar Plan of the Union for the Mediterranean (UfM, 2013) on the sustainability of the electricity generation mix in Tunisia.

\section{References}

ANME, 2010. Production d'électricité renouvelable en Tunisie - Perspectives et opportunités à l'horizon 2030. Agence Nationale pour la Maîtrise de l'Energie (ANME), Tunis 2010

ANME, 2013a. Nouvelle version du Plan Solaire Tunisien. Programmation, conditions et moyens de la mise en oeuvre. Agence Nationale pour la Maîtrise de l'Energie (ANME). Tunis, 2013.

ANME, 2013b. Stratégie nationale du mix énergétique pour la production électrique aux horizons 2020 et 2030. Agence Nationale pour la Maîtrise de l'Energie (ANME). Tunis..

Boran, F. E., Dizdar, E., Toktas, I., Boran, K., Eldem, C., Asal, Ö., 2013. A multidimensional analysis of electricity generation options with different scenarios in Turkey. Energy Sources, Part B: Economics, Planning, and Policy (2013), 8(1), 44-55.

Brand B, Boudghene Stambouli A, Zejli D., 2012. The value of dispatchability of CSP plants in the electricity systems of Morocco and Algeria. Energy Policy 47(2012): 321-331.

Del Riego DJ, Souto J, Casares J., 2012. Dynamic multi-criteria decision analysis of electricity generation mix choices for future sustainability. Proceedings of the IASTED International Conference Power and Energy Systems (EuroPES 2012), Naples, Italy.

DGE, 2013. Direction Générale de l'Energie (DGE). Quels mix énergétiques possibles pour 2030. Presentation by K. Rekik for the World Bank Energy Sector Management Assistance Program (ESMAP). Low carbon power sector study, 2013, Tunis. 
Diakulaki D, Karangelis F., 2007. Multi-criteria decision analysis and cost-benefit analysis of alternative scenarios for the power generation Sector in Greece. Renewable and Sustainable Energy Reviews 11(2007) 716-727.

Dii, 2013. Desertec Industrial Initiative (Dii). Desert Power: Getting started. Munich. 〈www.dii-eumena.com〉.

Fraunhofer/Ernst \& Young, 2011. Middle East and North Africa Region, Assessment of the Local Manufacturing Potential for Concentrated Solar Power (CSP) Projects, Report for the World Bank, January 2011.

GIZ/ANME, 2012. Renewable energy and energy efficiency in Tunisia - employment, qualification and economic effects. Deutsche Gesellschaft für Internationale Zusammenarbeit (GIZ), Agence Nationale pour la Maîtrise de l'Energie (ANME). Tunis. < www.giz.de/expertise/downloads/giz2012-en-employment-renewableenergy-tunisia.pdf

Haddad M., 2011. Country perspective Tunisia. In: The end of nuclear energy. International perspectives after Fukushima. (Eds. Netzer $\mathrm{N}$ and Steinhilber J). Friedrich Ebert Stiftung, July 2011. Berlin.

Häyhä T, Franzese P, Ulgiati S., 2011. Economic and environmental performance of electricity production in Finland: A multicriteria assessment framework. Ecological Modelling 223 (2011) 81-90.

Helioclim, 2012. SoDa Database. <http://www.soda-is.com/eng/helioclim/ . Paris.

Hwang CL, Yoon K., 1981. Multiple Attribute Decision Making: Methods and Applications. New York, Springer-Verlag.

Kim, G., Park, C. S., Yoon, K. P., 1997 Identifying investment opportunities for advanced manufacturing systems with comparative-integrated performance measurement. International Journal of Production Economics, 50(1), 23-33.

Krewitt, W., 2002. External costs of energy-Do the answers match the questions? Looking back at 10 years of ExternE. Energy Policy 30(10): 839-848.

Mirasgedis S, Diakoulaki D., 1997. Multicriteria analysis vs. externalities assessment for the comparative evaluation of electricity generation systems. European Journal of Operational Research 102(2):364-79.

NASA, 2012. MERRA. Modern Era Retrospective Analysis for Research and Application. $<$ http://gmao.gsfc.nasa.gov/research/merra/intro.php

NREL, 2012. System Advisor Model, version 2012.5.11. National Renewable Energy Laboratory. Golden, Colorado. <https://sam.nrel.gov/ .

Pappas C, Karakosta C, Marinakis V, Psarras J., 2012. A comparison of electricity production technologies in terms of sustainable development. Energy Conversion and Management, 64(2012), 626-632. 
Pohekar, SD, Ramachandran, M., 2004. Application of multi-criteria decision making to energy planning - A review. Renewable and Sustainable Energy Reviews 8(2004) 365-381.

Ribeiro F, Ferreira P, Araújo M., 2012. Impact chains and a multi-criteria decision analysis tool to support electricity planning. Guimaraes, 2012. <sepp.dps.uminho.pt/relatorio_01_2012.pdf

Rutovitz J, Harris S, 2012. Calculating global energy sector jobs: 2012 methodology. Institute for Sustainable Futures, University of Technology, Sydney.

Sander+Partner, 2012. MINT software for statistical analysis of wind data. $<$ http://www.sander-partner.com/en/products/mint.html .

STEG, 2010. Etude des options de développement du parc de production de l'électricité de la Tunisie. Société Tunisienne de l'Electricité et du Gaz (STEG). Projet centrale électronucléaire \& Direction des Etudes et de la Planification, Tunis. October 2010.

Streimikiene D, Balezentis T, Krisciukaitiene I, Balezentis A., 2012. Prioritizing sustainable electricity production technologies. Renewable and Sustainable Energy Reviews 16 (2012) 3302-3311.

UfM, 2013. The Mediterranean Solar Plan (MSP). Union for the Mediterranean Secretariat, Barcelona. $2013<$ http://ufmsecretariat.org/the-msp-in-short/ .

Wang J, Jing, Y, Zhang C, Zhao J., 2009. Review on multi-criteria decision analysis aid in sustainable energy decision-making. Renewable and Sustainable Energy Reviews, 13, 2263-2278. doi:10.1016/j.rser.2009.06.021.

Wang Z., Lu M., Jiancai W., 2014. Direct rebound effect on urban residential electricity use: An empirical study in China, Renewable and Sustainable Energy Reviews, 30: 124132.

World Economic Forum, 2012. Adressing the 100 Million Youth Challenge. Perspectives on youth employment in the ArabWorld in 2012. World Economic Forum, Geneva.

Wuppertal Institut/Alcor, 2012. Etude Stratégique du Mix Energétique pour la Production d'Electricité en Tunisie. Report commissioned by the German Development Agency GIZ, Wuppertal/Tunis. $<$ http://epub.wupperinst.org/files/4785/4785_Mix_Energetique_Tunisie.pdf 